\title{
Comparison of snow-removal technologies practised in the cities along the Sea of Japan
}

\author{
Norio Hayakawa, \\ Department of Civil Engineering, Nagaoka University of Technology, \\ Nagaoka, Niigata 940-21, Japan \\ TERUYOSHI UMEMURA, \\ Department of Mechanical Engineering, Nagaoka University of Technology, \\ Nagaoka, Niigata 940-21, Japan \\ Yusuke Fukushima \\ Department of Civil Engineering, Nagaoka University of Technology, \\ Nagaoka, Niigata 940-21, Japan
}

\begin{abstract}
The region along the Sea of Japan is unusual in that it has very heavy snow and rather mild winter temperatures. Three major snow-removal technologies currently practised in the region, i.e. use of snow-removal machines, snow-melting pipe system and snow-dumping channel network, are described and their practice, engineering and economical aspects discussed.
\end{abstract}

\section{INTRODUCTION}

The Sea of Japan side of the main island of Japan has very heavy snowfall and mild winter temperatures. Consequently, snow is often wet and heavy. Snow-removal technologies practised in this region, therefore, have unusual features. Good examples are the snow-melting pipe system and the snow-dumping channel network. This paper investigates these two technologies and the use of snow-removal machines. Reported here are state of practice, engineering and economical aspects of these technologies.

\section{SNOW AND CLIMATE OF THE REGION}

Japan's main island is bisected by major mountain ridges. West of the divide lies the Sea of Japan. Seasonal dry wind blows down from Siberia and picks up moisture from the warm water of the Sea of Japan. This results in wet, heavy snow along the Sea of Japan coastal area. Figure 1 shows the monthly average values of temperature and humidity in Tokyo (Pacific side) and Nagaoka (Sea of Japan side), showing that the latter records mild winter temperature and high humidity throughout the year. Figure 2 shows the annual change in cumulative depth of new snow in Nagaoka 1925-82, the statistic of significance in terms of snow-removal strategy. Figure 2 shows quite a variation year-to-year, the largest being $1229 \mathrm{~cm}$ and the smallest $212 \mathrm{~cm}$. Figure 3 is a log-normal plot of the data of Figure 2, suggesting a good fit to the log-normal distribution if the data is biased. Figure 3 gives the $10 \mathrm{yr}$ exceeding value of $903 \mathrm{~cm}, 2 \mathrm{yr}$ exceeding value (average value) of $575 \mathrm{~cm}$ and $10 \mathrm{yr}$ non-exceeding value of $342 \mathrm{~cm}$, corresponding to probabilities of exceedence of, respectively, $10 \%, 50 \%$ and $90 \%$. It can be said that to keep the road completely free of snow in Nagaoka, one has to move $575 \mathrm{~cm}$ of snow per average year, $903 \mathrm{~cm}$ once in $10 \mathrm{yr}$ and not less than $342 \mathrm{~cm}$ in $10 \mathrm{yr}$. Figure 4 is a log-normal plot of the maximum depth of new snow in the year and shows a good fit to the lognormal distribution. This figure also gives the $10 \mathrm{yr}$ exceeding value of $71 \mathrm{~cm}, 2 \mathrm{yr}$ exceeding value (average value) of $54 \mathrm{~cm}$ and $10 \mathrm{yr}$ non-exceeding value of $31 \mathrm{~cm}$. These values give good estimates of necessary snow-

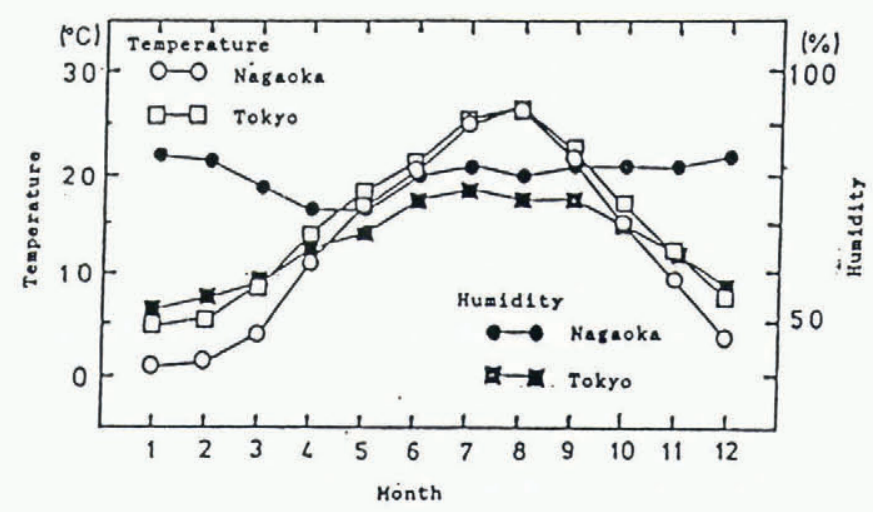

Fig. 1. Temperature and humidity in Nagaoka and Tokyo. 


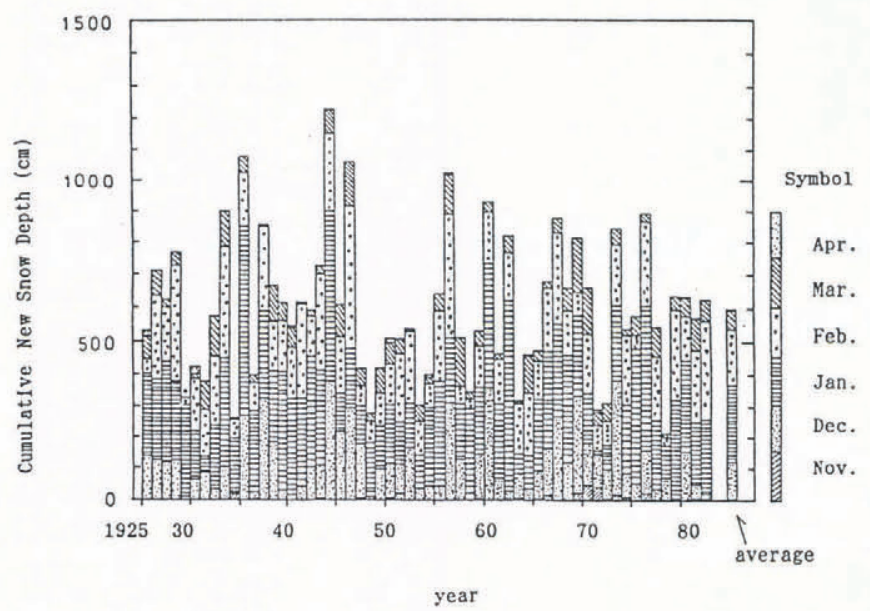

Fig. 2. Cumulative depth of new snow.

removal effort. There are several other cities with sizable populations and about equal or greater snowfall per year.

\section{SNOW-REMOVAL TEGHNOLOGIES PRACTISED IN THE REGION}

Snow-removal is indispensable for the well-being of the people inhabiting the region. It is often said that only after the disastrous heavy snowfall in 1963, which crippled much of the area's transportation, did the modern snow-removal technology begin to be introduced on the operational scale.
(\%)

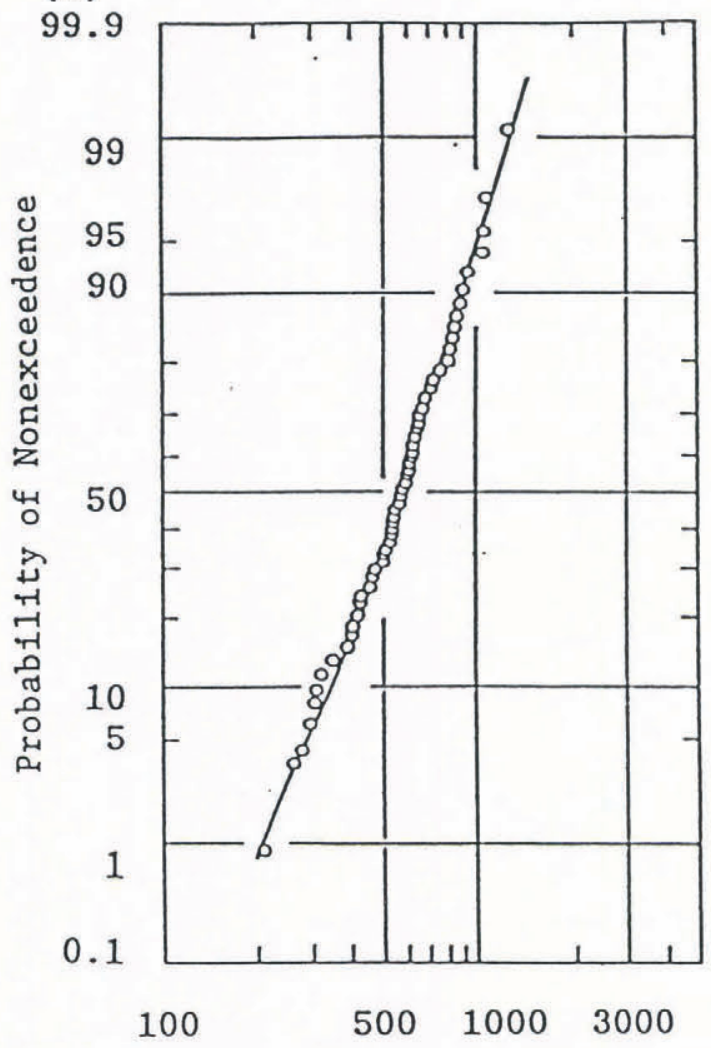

Cumulative New Snow Depth (cm)
(\%)

0.1

1

5

10

50

90

95

99

99.9
(\%)

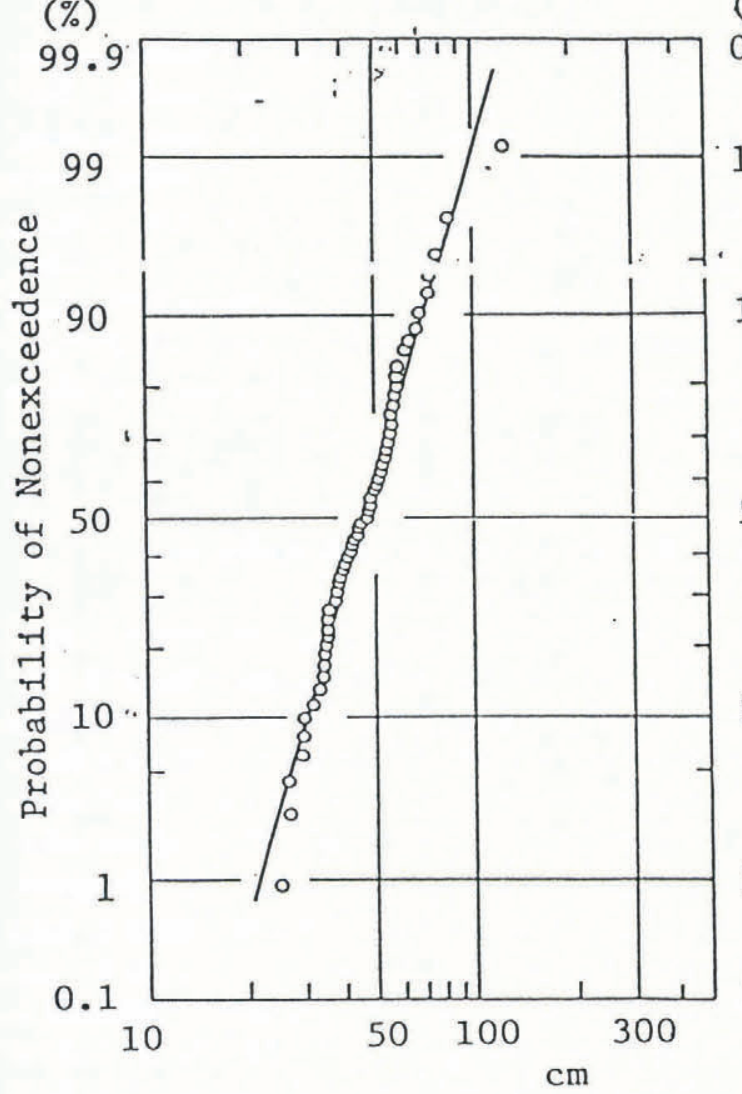

Max. New Snow Depth
$(\%)$

0.1 being poured into snow removal, to make life in the snowy country equally comfortable as that in snow-free areas. A number of snow-removal technologies are employed in urban areas including (1) the use of snowremoval machines, (2) a snow-melting pipe system embedded in the road surface, and (3) a snow-dumping channel network. Use of snow-removal machines is nothing new and is employed in the same way as elsewhere. The other two technologies, however, appear to be unique even in Japan.

The pipe system for melting snow originated in Nagaoka around 1963, when there was an unusually heavy snowfall. This system pumps up groundwater and sprinkles it over the road surface out of a pipe system embedded along the center of the road (Fig. 5).

The snow-dumping channel network is believed to have originated before World War II. It consists of a network of road-side ditches with running water which can be pumped in, if necessary. People can use these ditches to dispose of snow piled up on the road or dumped off the rooftops (Fig. 5). Both of these technologies have their merits, drawbacks and conditions to be met in order to be effective for a particular service area.

Prerequisite to the pipe system for melting snow is availability of groundwater and mild winter temperatures so that the pipe system does not freeze. The region around Niigata Prefecture best satisfies these conditions. One of the drawbacks of this technology is danger of land subsidence due to too much drawdown of groundwater; nowadays, any new system is required to be fitted with a

Fig. 3. Log-normal plotting of cumulative new-snow depth.

Fig. 4. Log-normal plotting of maximum snow depth in the year. 


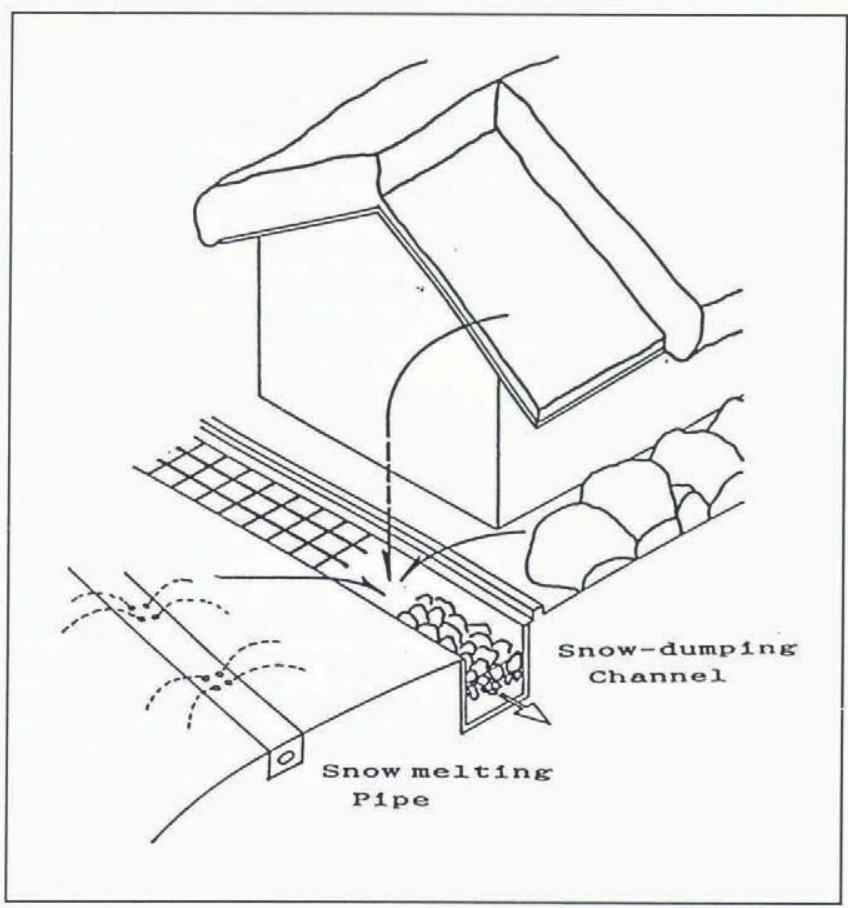

Fig. 5. Schematic diagram of snow-dumping channel and snow-melting pipe.

snow-detecting device to avoid unnecessary pumping of groundwater. Another drawback is the unpopularity with pedestrians, who must wade through the slushy road.

Prerequisite to the snow-dumping channel network is availability of water. Also, this technology can be placed only in sloped areas, so that the snow-dumping channel has a sufficient slope. The drawback of this technology is the possibility of blocking and consequent flooding if too much snow is dumped. In some cities, people have to take turns dumping snow as water is directed from one area to another. Perhaps the best merit of this technology is that snow is actually removed without resorting to any power.

Table 1. Snow-removal practice in selected cities (1980)

\begin{tabular}{|c|c|c|c|c|}
\hline Name of city & Nagaoka & Ojiya & Foetsu & Arai \\
\hline City area $\left(\mathrm{km}^{2}\right)$ & 260 & 154 & 252 & 173 \\
\hline Population & 180259 & 44963 & 35687 & 28575 \\
\hline \multicolumn{5}{|c|}{$\begin{array}{l}\text { Max. snow depth } \\
(\mathrm{cm})\end{array}$} \\
\hline per average year & 135 & 215 & 140 & 185 \\
\hline recorded max. & 318 & 382 & 425 & 360 \\
\hline \multicolumn{5}{|c|}{$\begin{array}{l}\text { Road length }(\mathrm{km}) \\
\text { for snow removal by: }\end{array}$} \\
\hline $\begin{array}{l}\text { machines } \\
\text { melting-pipe }\end{array}$ & 395 & 218 & 403 & 95 \\
\hline $\begin{array}{l}\text { system } \\
\text { snow-dumping }\end{array}$ & 100 & 2.5 & 7.5 & 9.1 \\
\hline channel & 0.7 & 28.1 & 0 & 4.9 \\
\hline
\end{tabular}

There has been mounting interest in placing this technology in new areas. The popularity of these unique technologies in this region lies in the scarcity of snowremoval vehicles before 1963 and the crowded city structure: streets are often narrow and houses built close together, making use of snow-removal machines difficult. In some areas one or two days are chosen for people to shovel down snow from the rooftop of every house. The traffic is then completely halted until snow piled up on the road is removed by trucks. This can be said to be a drawback of relying on snow-removal machines only.

\section{ECONOMICAL COMPARISON OF SNOW- REMOVAL TECHNOLOGIES}

Table 1 gives statistics of snow-removal effort for some of the cites in Niigata Prefecture. Various cities rely on various methods of removing snow, depending upon their

Table 2. Comparison of economical assets of snow-removal technologies

$\begin{array}{cc}\text { Snow-dumping } & \text { Snow-melting } \\ \text { channel } & \text { pipe }\end{array}$

Snow-removing capacity

$\left(\mathrm{t} \mathrm{h}^{-1} \mathrm{~km}^{-1}\right) \quad 200$

Construction cost

$$
\left(10^{3} ¥ \mathrm{~m}^{-1}\right)
$$

Maintenance cost

$\left(10^{3} ¥ \mathrm{~m}^{-1} \mathrm{yr}^{-1}\right)$

Construction cost/capacity

$\left(10^{6} ¥ \mathrm{t}^{-1} \mathrm{~h}^{-1}\right)$

Maintenance cost/capacity

$$
\left(10^{6} ¥ \mathrm{t}^{-1} \mathrm{~h}^{-1} \mathrm{yr}^{-1}\right)
$$

social and technological conditions. However, the snowdumping channel network is generally adopted by cities with sloped terrain. It seems that no single technology could solve the problem of snow removal entirely and a city must rely on several technologies combined.

Undoubtedly, snow-removal capacity and cost of construction and maintenance vary widely depending upon the area's conditions. Still, it would be useful to make an attempt and thus typical cases are examined here (Umemura and others, 1985). They are the snowmelting pipe system of Nagaoka City with serviced length of $107.1 \mathrm{~km}$ and the snow-dumping channel of Ojiya City with serviced length of $1.6 \mathrm{~km}$. Comparison of economic assets of these two facilities is given in Table 2 with data taken in 1983. Table 2 indicates that the snow-melting pipe is more economical to build as well as maintain, in terms of the length serviced. However, the snow-dumping channel has much greater snow-removing capacity and thus is more economical in maintenance cost per capacity. 
The use of snow-removal machines cannot be compared with the other two technologies directly. A rough idea may be obtained from the fact that Nagaoka City spends about $400 \times 10^{6} ¥$ to remove snow with snow-removing machines from its $709 \mathrm{~km}$ road, which gives a unit cost of $560 ¥ \mathrm{~m}^{-1} \mathrm{y}^{-1}$, slightly higher than maintenance cost of the snow-melting pipe. Therefore, economically these technologies are competitive and it is the choice of the people which one to employ.

\section{CONCLUSION}

The region in Japan along the Sea of Japan is unusual for its combination of very heavy snow and rather mild winter temperature. Three major snow-removing technologies currently practised in the region, i.e. use of snowremoval machines, a snow-melting pipe system, and a snow-dumping channel network are described, and their state of practice and engineering as well as economical aspects are discussed. It is shown that these three technologies are practised equally in the region with equal economic competitiveness and the recent trend shows a mounting interest in snow-dumping channels.

\section{ACKNOWLEDGEMENTS}

The major part of this work was carried out under the support of Technology Development Center project of Nagaoka University of Technology. Authors wish to thank Nagaoka City, Niigata Engineering Co. Ltd, Ebara Manufacturing Co. Ltd, Sato Engineering Co. Ltd, Maruiso Construction Co. Ltd and ARGOS Co. Ltd for their support.

\section{REFERENCE}

Umemura, T., N. Hayakawa, A. Okada, A. Honda, A. Uchikura and H. Taniuchi. 1985. A feasibility study of a system of urban snow removal and storage, integrated with air conditioning. Part II. Snow conveying and storage facilities and economy of the system. Seppyo. F. Jpn. Soc. Snow Ice, 47(2), 71-78.

The accuracy of references in the text and in this list is the responsibility of the authors, to whom queries should be addressed. 